\title{
Tradução poética de músicas para língua brasileira de sinais (Libras)
}

Natália Schleder Rigo*

\section{Introdução}

"Abacateiro teu recolhimento é justamente o significado da palavra temporão. Enquanto o tempo não trouxer teu abacate, amanhecerá tomate e anoitecerá mamão". Foi preciso um grupo de linguistas da Universidade Federal de Viçosa (UFV) para descobrir a existência de alguém que compreendesse o que diz Gilberto Gil em sua música "Refazenda" de 1975 (PIAUÍ, 2009). Se apenas um lavrador de Monte do Carmo, no Tocantins, e um grupo interdisciplinar de pesquisadores da UFV foram capazes de compreender a letra do compositor baiano, o que seria de um tradutor se tivesse que traduzir essa música? Realmente uma tarefa nada fácil, pois além de ter que compreender o sentido da letra, precisaria construí-la em outra língua.

Tradutores e intérpretes de línguas de sinais, doravante TILS, são profissionais que enfrentam inúmeros desafios em sua prática. Um desses desafios, certamente, é a tradução de músicas. O trabalho com a transposição de músicas para língua de sinais é hoje uma prática bastante recorrente e expressiva no contexto brasileiro, sobretudo, entre surdos e ouvintes falantes da Língua Brasileira de Sinais (Libras). Essa prática, cada vez mais comum, já foi motivo de julgamento, desconforto e opiniões bastante divergentes, uma vez que "música para surdos" ainda era, há pouco tempo, uma questão polêmica, um tabu.

Há mais de dez anos, defendia-se a ideia de que "música não faz parte da cultura surda". Uma das primeiras pesquisadoras surdas do Bra-

\footnotetext{
${ }^{*}$ Universidade do Estado de Santa Catarina (UDESC).
} 
sil, Karin Strobel, pesquisou sobre os artefatos culturais dos povos surdos e, com relação à música, a autora se posicionava da seguinte forma:

Música não faz parte da cultura surda, mas os sujeitos surdos podem e tem o direito de conhecê-la como informação e como relação intercultural. São raros os sujeitos surdos que entendem e gostam de música e isto também deve ser respeitado. Respeitando a cultura surda, substituindo as músicas ouvintizadas, surgem os artistas surdos em diferentes contextos como: música-sem-som, dançarinos, atores, poetas, contadores de histórias etc. (STOBREL, 2008, p.70).

Apesar de a autora entender a música como artefato cultural ouvinte, desde 2008 já advertia sobre o direito dos surdos se informarem e se relacionarem interculturalmente com ela. Strobel (2008) já mencionava também sobre o surgimento de formas de expressão musical surda, por exemplo, as "músicas-sem-som", definidas como "coreografias de dança em língua de sinais sem música".

É possível afirmar que a relação intercultural dos surdos com a música cresceu de 2008 pra cá e, em paralelo, a tomada de consciência desses sujeitos sobre seus direitos e liberdade de escolhas, incluindo a liberdade de se apropriarem da música como bem entenderem, de experimentá-la à sua maneira - sem imposição ou julgamento de ouvintes — e, ainda, de ressignificá-la para além do som ou da dimensão do audível. Hoje em dia, os surdos apreciam, usufruem, consomem e produzem música de infinitas formas. Manifestam-se artisticamente não mais através da literatura, do teatro, da dança, das artes visuais e das artes performáticas somente, mas também através da linguagem musical.

A comunidade surda se expandiu significativamente, uma vez que reflete hoje um número considerável de surdos que são: músicos, instrumentistas, educadores musicais, estudiosos e pesquisadores do assunto, membros de bandas e grupos musicais, compositores, tradutores, consultores e intérpretes em shows e festivais, performers em videoclipes, líderes em louvores religiosos, guias e condutores do hino nacional em eventos etc. Há aqueles, inclusive, que possuem carreiras já reconhecidas dentro do mercado musical majoritariamente ouvinte. Conforme lembra Santana (2019), os surdos estão "cada vez mais acessando espaços e contextos nunca antes 
imaginados: teatros, casas de shows, festivais, eventos culturais, museus, espetáculos dos mais diversos tipos, carnavais, festividades populares e até apresentações de paródias de cunho político-partidário" (p.56).

Diante de uma comunidade surda ressignificada, que revela uma estreita e evidente relação com o universo musical, é possível afirmar hoje, mais do que nunca, que música não é algo exclusivo das pessoas que ouvem. Ela deixou há tempos de ser um artefato cultural de privilégio ouvinte (se é que um dia foi). A música está presente, desde sempre, em todos os mundos, em todas as culturas, e se manifesta em todos os corpos. A música faz parte sim da cultura surda.

Daniela Prometi (no prelo), enquanto profissional musicista surda, com anos dedicados à música e também pesquisadora do assunto, também defende que música é algo presente entre os surdos e, portanto, faz parte da cultura e da comunidade surda. Ao pesquisar sobre terminologia e glossários bilíngues musicais, a autora oportunamente desconstrói a já ultrapassada questão: "música para surdos?", propondo que o debate avance para a dimensão da "música com surdos" e da "música por surdos". A autora posiciona-se com propriedade para defender o protagonismo e da representatividade surda também no campo musical.

Os avanços da comunidade surda geram progressos na área de atuação de TILS e visibilidade da profissão. Com a presença cada vez maior dos surdos nas diferentes esferas sociais, e com as crescentes políticas linguísticas, de tradução e acessibilidade cultural, fica cada vez mais clara a importância dos TILS enquanto profissionais que viabilizam o acesso linguístico de surdos à arte e à cultura. Nessa perspectiva, cabe compartilhar o que considera Santana (2019) sobre a tradução de música:

\footnotetext{
A música transposta para Libras a partir da tradução intersemiótica se constitui em um tráfego cultural existente entre a cultura surda e a ouvinte. [...] Música é arte e a arte só sobrevive em razão das reproduções (traduções) refeitas sobre ela. Qualquer tradução promove uma desordem, destituindo da ordem da tradição e beleza. A tradução permite a suspensão da descrença. Vinícius de Moraes é "ressuscitado" cada vez que a música Aquarela é traduzida para Libras. Além disso, ele pode ser apresentado à comunidade surda pela primeira vez, assim como tantos outros artistas, compositores, personagens reais e fictícios cantados, contados e ima-
} 
ginados. Talvez, sem esse diálogo e essa recriação possibilitada pela tradução intersemiótica em Libras, poucos surdos conheceriam tais autores e suas obras e não poderiam sequer atribuir sua impressão pessoal sobre elas. (SANTANA, 2019, p.59)

A área artística de atuação de TILS é relativamente nova, mas vem se consolidando rapidamente como um expressivo campo de trabalho. A atuação nessa área já é inclusive contemplada em classificações de remuneração de entidades representativas da categoria, por exemplo, na tabela ${ }^{1}$ de referência de honorários da Federação Brasileira das Associações dos Profissionais Tradutores, Intérpretes e Guia-Intérpretes de Língua de Sinais (Febrapils).

Os avanços também refletem na esfera acadêmica, uma vez que o crescimento da área implica igualmente no aumento de temáticas necessárias de serem trazidas para debate e discussão teórica, por meio de pesquisas e estudos que ajudam a compreender melhor os caminhos da prática. Enquanto TILS, e diante do crescimento de demandas de tradução musical para Libras, resolvi trazer esse assunto para discussão em minha pesquisa de mestrado, realizada entre 2010 e 2012, e compartilhada em Rigo (2013). O estudo teve como objetivo identificar e analisar recursos de tradução de músicas de Português para Libras, empregados por surdos e ouvintes, de modo a apontar quais recursos podem contribuir para traduções musicais mais responsáveis, que considerem o público surdo e suas particularidades referentes à experiência visual, cultura e modalidade linguística.

Em Rigo (2013), apresento alguns apontamentos sobre tradução musical, incluindo considerações sobre a atividade pensada numa perspectiva de tradução poética. É partindo deste ponto que compartilho neste artigo um breve recorte da pesquisa, apresentando uma reflexão sobre tradução de músicas, que leve em consideração a tradução poética e o emprego de recursos artísticos e criativos da língua de sinais. As considerações aqui apresentadas são atualizadas e complementares ao trabalho compartilhado em Rigo (2013). Este artigo soma aos demais estudos que se inscrevem na área dos Estudos da Tradução e Interpretação de Língua de Sinais

\footnotetext{
${ }^{1}$ Disponível em: https://febrapils.org.br/tabela-de-honorarios/. Acesso em 10 set. 2019
} 
(ETILS) e contribui com profissionais TILS que atuam com traduções de músicas, sobretudo, no contexto artístico-cultural.

\section{Tradução de Músicas no Contexto Artístico-Cultural}

Ao pesquisar sobre formação de TILS, Rodrigues (2010) identificou diferentes contextos de atuação profissional, a saber: contexto educacional, jurídico, familiar, midiático, religioso, empresarial, de saúde, de lazer e turismo, e de conferência. Em 2010, neste levantamento introdutório de áreas, o contexto artístico-cultural ainda não havia sido identificado como campo de atuação de TILS. No âmbito internacional, porém, Napier et al. (2006) e Humphrey e Alcorn (2007) já incluíam esse contexto em suas categorizações, o denominando de performance interpreting settings e theatrical or performing art settings.

O "contexto artístico-cultural" foi dessa forma denominado pela primeira vez, e inserido como área de atuação de TILS no âmbito brasileiro, em Rigo (2013), com base no levantamento bibliográfico e documental que realizei para o estudo. Atualmente, é possível definir o contexto artísticocultural como a área de atuação que compreende majoritariamente demandas de tradução e/ou interpretação de textos artísticos e literários (orais/sinalizados ou escritos). As demandas envolvidas nesse contexto podem compreender diferentes linguagens artísticas (música, teatro, dança, cinema, artes visuais, performances etc.) e literaturas, em suas múltiplas possibilidades de apresentação, materialização e veiculação. Esse contexto implica exigências e competências profissionais que são comuns aos outros contextos de atuação e, ao mesmo tempo, exigências e competências tecnicamente particulares e especializadas.

No contexto artístico-cultural, o trabalho com tradução de músicas na direção Português $\rightarrow$ Libras pode acontecer, por exemplo, em shows, espetáculos, festivais, musicais teatrais, apresentações artísticas diversas, intervenções culturais etc. Esses eventos, inclusive, podem compreender momentos específicos inseridos em outros contextos. Conforme compartilhado em Rigo (2013), traduções musicais não se restringem ao contexto artístico-cultural, uma vez que a música pode aparecer de múltiplas formas, nas mais diversas esferas sociais. A música pode estar presente, por 
exemplo, em sala de aula, como instrumento pedagógico no contexto educacional.

Cabe esclarecer que o termo "tradução" da expressão "tradução musical" empregada neste artigo, é usado como hiperônimo, ou seja, no sentido mais abrangente do termo e a partir da perspectiva operacional, que compreende tanto a atividade de "tradução" quanto de "interpretação". Embora na construção deste artigo, assim como em Rigo (2013), haja a devida clareza da diferença entre tradução e interpretação - não apenas como atividades distintas, mas também como campos que se diferem e se complementam - a expressão "tradução musical" será usada dessa forma partindo do entendimento de que o trabalho operacional realizado pelo TILS com música é híbrido.

Rodrigues e Beer (2015), ao considerarem sobre os campos dos Estudos da Tradução (ET) e dos Estudos da Interpretação (EI) entendem que:

\begin{abstract}
[...] o que permite diferenciar os ET e os EI é basicamente o seu objeto central de estudo, respectivamente, "a tradução e o traduzir" e "a interpretação e o interpretar". Esses dois processos, embora cunhados na translação de material linguístico-cultural de uma língua à outra, caracterizam-se pela maneira por meio da qual acontecem linguística, cognitiva e operacionalmente. Nesse sentido, esses campos disciplinares são justapostos e interdependentes, já que sua coexistência é inevitável e, ao mesmo tempo, são distintos e singulares em relação à especificidade do seu foco de estudos. (RODRIGUES \& BEER, 2015, p.19)
\end{abstract}

Na dimensão operacional do trabalho do TILS com textos artísticos, incluindo textos musicais, Napier et. al (2006) consideram que, embora a tradução e a interpretação sejam entendidas como atividades distintas, realizadas em momentos separados, o que acontece é um trabalho híbrido. Isso porque é necessário um momento de preparação prévia, que envolve primeiramente a tradução do texto (da letra da música ou do roteiro da peça teatral, por exemplo) e depois a interpretação propriamente dita, no momento em que a apresentação artística acontece ao vivo para o público. Mais considerações a respeito da preparação, das etapas do trabalho e desdobramentos operacionais da atuação do TILS com música e teatro, podem 
ser consultadas em Rigo (2013, 2014 e 2018), Silva Neto (2017) e Fomin (2018).

A prática de tradução de músicas, para alguns profissionais, pode ser entendida como uma das mais desafiadoras dentro do contexto artístico-cultural, uma vez que a música compreende além de signos verbais, signos não verbais. Os signos verbais sugerem questões linguísticas específicas. Por exemplo, as letras das músicas podem ser originalmente construídas de inúmeras formas, utilizando vários recursos linguísticos e o emprego criativo e intensificado da linguagem, a partir de: expressões idiomáticas, metáforas, ambiguidades, metonímias, figuras de linguagem, rimas, versos etc.

Já os signos não verbais sugerem todos os elementos sonoros presentes na música, tais como: melodia, ritmo, harmonia etc, e consequentemente, as propriedades físicas desses elementos: altura; intensidade e timbre. Vale refletir o quanto todos esses elementos, linguísticos e sonoros, podem se relacionar dentro de uma única música e, uma vez combinados, podem ser determinantes em uma tradução destinada ao público surdo.

Pensar sobre tradução musical para língua de sinais implica pensar, necessariamente, nos surdos. É visível que muitas traduções musicais são realizadas considerando as pessoas ouvintes como público alvo, e não os surdos; tanto, que é possível observar trabalhos publicados em vídeo na internet (em plataformas como o Youtube, por exemplo), que são consumidos e assistidos por pessoas que sequer conhecem a língua de sinais.

Sem me aprofundar, por ora, na questão da qualidade desses trabalhos, tampouco nas implicações que esse tipo de tradução (pensada para os ouvintes) acarreta, é urgente um olhar mais atento por parte dos profissionais TILS que traduzem música, principalmente, uma postura ética mais consciente e responsável na prática profissional. Vale lembrar que, a experiência musical e sonora dos surdos difere da experiência do tradutor ouvinte e, naturalmente, dos autores/compositores das músicas em sua produção original. É nesse sentido que, todas as questões imbricadas no contexto de chegada da tradução musical para Libras devem ser muito bem pensadas. 
Napier, et. al. (2006) apontam que a tradução de músicas para línguas de sinais segue um processo similar ao trabalho de tradução de textos teatrais, uma vez que é igualmente necessário que o texto traduzido faça sentido visual para os surdos. Para Humphrey e Alcorn (2007), a tradução musical requer muitas horas de prática, e o profissional TILS pode precisar de cópias antecipadas das músicas para preparar e estudar não apenas as letras das canções, os termos e os contextos linguísticos e semânticos, mas também os sons, os tempos das batidas e os elementos não verbais.

Outra característica desse tipo de tradução é a inclusão do conteúdo instrumental da música. O TILS precisa tomar decisões quando os instrumentos musicais e seus sons (solos de bateria, de guitarra, de saxofone, por exemplo) fazem parte do show ou do contexto em que a música está sendo executada sem letra.

Alguns profissionais costumam escolher, nesses casos, movimentos rítmicos que estejam sincronizados com o compasso da música; outros simplesmente mudam o olhar e/ou a postura corporal para dar foco visual ao artista, algo parecido com o que Ganz Horwitz (2014) chama de throwing focus na tradução teatral, ou seja, "direcionar a atenção" dos surdos para cena. Há ainda quem utilize descrições imagéticas ${ }^{2}$ dos instrumentos, tal como fez o TILS Tom Min Alves na tradução de músicas e efeitos de sonoplastia presentes em filmes.

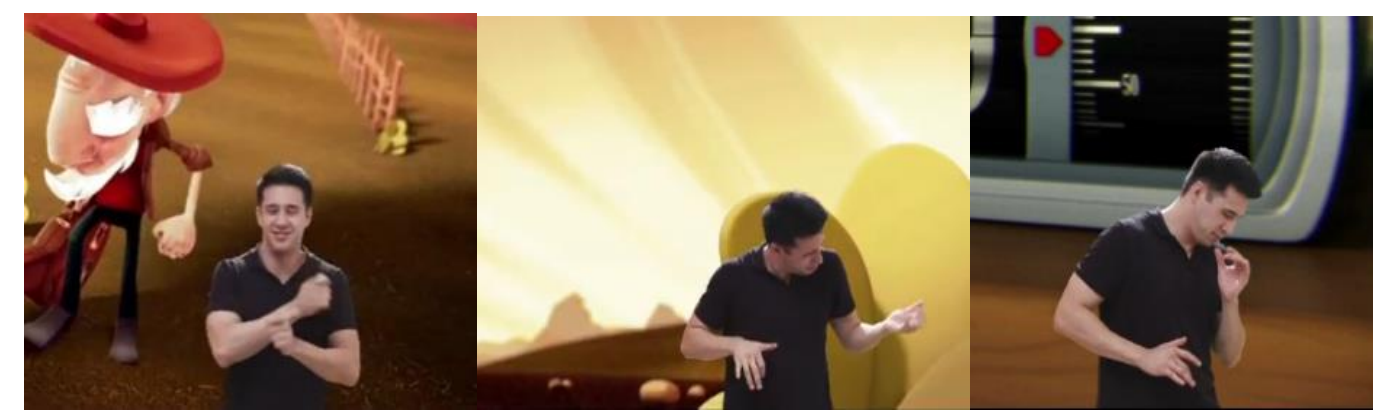

Figura 1: Descrição imagética de instrumentos musicais (bateria, guitarra e saxofone). Fonte: Rigo (2013)

\footnotetext{
${ }^{2}$ A definição de "descrições imagéticas" será apresentada na próxima seção deste artigo.
} 
Para Humphrey e Alcorn (2007) essas decisões podem ser bem pensadas no momento de preparação do trabalho, considerando que o TILS pode trabalhar antecipadamente com o áudio da música. Outra opção é assistir a shows do(s) artista(s) antes de traduzir as músicas ao vivo, no momento da apresentação.

Vilas Boas e Olah (2019) consideram como desafios na tradução de músicas para Libras justamente as introduções, os interlúdios e os solos instrumentais, uma vez que "não possuem conteúdo verbal, isto é, não são acompanhados de letra na maioria das vezes" (p.113). Conforme as autoras,

\begin{abstract}
Esses intervalos instrumentais ampliam as sensações da música e, ao ouvilas, despertam no espectador diferentes emoções e memórias, além de permitirem um momento de introspecção. Mais ainda, trechos instrumentais conectam uma parte da música com a outra, como traços de um mesmo desenho e que, em conjunto, formam uma única obra. (VILAS BOAS e OLAH, 2019, p.113)
\end{abstract}

Em seus trabalhos com produção de vídeos musicais em Libras, as autoras apresentam algumas maneiras de apresentar esses trechos instrumentais, por exemplo, por meio de recursos gráficos, inserção de imagens e outros vídeos, ou ainda, a partir de efeitos de edição audiovisual que preservem visualmente as referências do texto original.

Anderson (2009) diferencia "tradução literal" do que ele chama de "tradução idiomática". Para o autor, as traduções literais são aquelas alinhadas exatamente na mesma ordem e estrutura lexical do texto original; o que, nesse caso, geralmente ocasiona conflitos entre as línguas envolvidas, uma vez que são idiomas diferentes, cada um com sua estrutura e especificidade gramatical. Já as traduções idiomáticas, são as que preservam o sentido do texto, embora as escolhas tradutórias se diferenciem da versão original. Nesse caso, conforme Anderson (2009), o texto costuma ser disposto de modo que a sinalização seja mais natural e não pareça proceder de uma tradução, mas sim de um texto criado originalmente na língua alvo.

Esse conflito gerado em traduções literais foi possível de ser observado nos resultados que obtive em Rigo (2013), considerando os recursos tradutórios analisados em traduções de músicas e o grau de literalidade e 
simultaneidade na sinalização de surdos e ouvintes. Conforme demonstrado na investigação, traduções mais simultâneas (ou seja, as que acompanham em maior proximidade o tempo de execução das músicas) tendem a ser mais literais. E as traduções com menor grau de simultaneidade (isto é, aquelas em que não há preocupação de alinhamento exato entre o tempo da música e o andamento da sinalização) tendem a ser mais "livres" e preservam melhor o sentido da letra da canção.

Anderson (2009) considera sobre os casos em que o profissional TILS pode não saber o significado de determinado texto ou letra musical, e isso pode acontecer em casos em que os textos assumem construções semânticas altamente complexas, como no caso da música "Refazenda" (1975) de Gilberto Gil antes mencionada. A tarefa do tradutor, nesses casos, é tentar oferecer um serviço minimamente adequado dentro das condições de trabalho oferecidas.

\section{Tradução poética de músicas para Libras}

Atuar no contexto artístico-cultural com música, demanda do TILS exigências e competências específicas. Algumas dessas exigências foram apresentadas e discutidas em Rigo e Taffarel (no prelo). Em nosso estudo, com base em Dean e Pollard (2001), classificamos quatro exigências principais de atuação no contexto artístico-cultural: exigências linguísticas, ambientais, interpessoais e intrapessoais. Partindo dessa classificação, com base nos dados coletados em Taffarel (2018), identificamos e discutimos sobre algumas dificuldades em comum enfrentadas por profissionais TILS atuantes, especificamente, na região catarinense do Vale do Itajaí.

Considerando as exigências linguísticas na tradução artística de forma geral (que inclui a tradução musical na direção Português $\rightarrow$ Libras), foi possível observar as seguintes dificuldades apontadas pela maioria dos profissionais entrevistados no estudo: o emprego de recursos poéticos e artísticos, terminologia e descrições imagéticas, tal como ilustra o gráfico abaixo: 


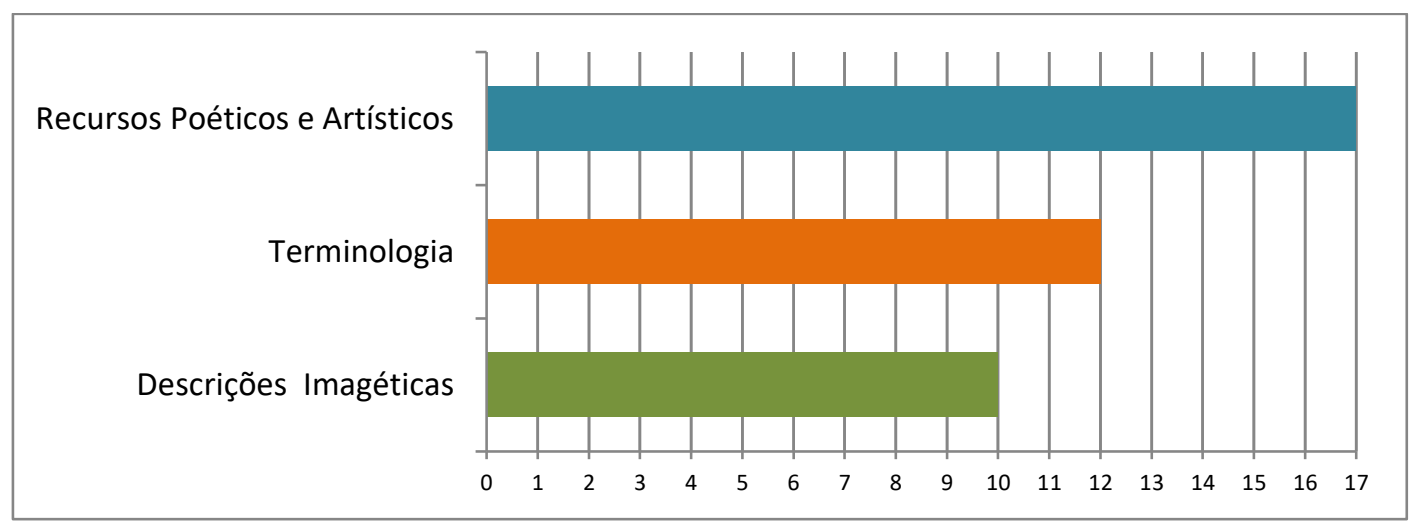

Gráfico 1: Principais dificuldades linguísticas enfrentadas por TILS no contexto artísticocultural. Fonte: Taffarel (2018)

Antes de falar sobre os recursos poéticos e artísticos, que estão diretamente relacionados à tradução poética de músicas, cabe contextualizar brevemente, para fins de esclarecimento, sobre as descrições imagéticas. De acordo com Pizzuto et al. (2006) há duas formas de produção de significado nas línguas de sinais: uma se dá pelas estruturas altamente icônicas, o que Campello (2008) denomina de "descrições imagéticas", e a outra se dá pelo léxico padrão. Campello (2008) entende a importância de percepção dos sinais visuais para ampliação da capacidade mental e visualidade na comunicação com os surdos. De acordo com a autora, todo e qualquer recurso usado para auxiliar a comunicação e compreensão de conceitos, precisa ser empregado com naturalidade para ajudar na tradução gramatical visual.

As descrições imagéticas são formas linguísticas das línguas de sinais que se apresentam num processo que transcende à dimensão lexical e, embora sejam empregadas sem maiores dificuldades pelos sinalizantes nativos (os surdos e os ouvintes que são filhos de pais surdos sinalizantes), exigem organizações visuais-espaciais complexas. Nesse sentido, nem todo falante ouvinte bilíngue, que aprende a língua de sinais como segunda língua (por exemplo, profissionais TILS não nativos) tem o domínio desse recurso. Cabe considerar, além disso, que essa forma linguística está fortemente presente na literatura surda, ou seja, em poesias, narrativas, contos, fábulas, performances etc. que, por sua vez, são produções que demandam o uso criativo e expressivo da língua de sinais. 
Conforme mostra o gráfico acima, o emprego de recursos poéticos e artísticos na tradução artística (e, portanto, na tradução musical) é uma dificuldade linguística comum enfrentada pelos TILS participantes de nosso estudo. Conforme compartilhamos em Rigo e Taffarel (no prelo),

Esse tipo de exigência decorre da necessidade do uso da forma intensificada da língua para efeito estético no trabalho com textos artísticos; o que Klima e Bellugi (1976, p.343) chamam de "sinal-arte". Falar sobre forma intensificada da língua ou "sinal-arte" significa falar sobre rupturas de padrões linguísticos e modos criativos de uso da língua em todos os níveis. No caso de trabalhos com textos artísticos, cuja direcionalidade da tradução é Português $\rightarrow$ Libras, é demandado do profissional criatividade nas construções linguísticas (RIGO \& TAFFAREL, no prelo).

Entendemos que o TILS que atua com tradução de música numa perspectiva poética precisa dominar minimamente recursos e processos linguísticos como: simetrias, soletrações artísticas, ritmo, rimas, morfismos, personificações, variações temporais, regras de repetição, antropomorfismos, expressões faciais e corporais, uso do espaço de sinalização e circulação, níveis de sonoridade visual, descrições imagéticas, classificadores, construções estéticas diversas, neologismos etc.

A letra da música, ao traduzida para a língua de sinais, pode ser entendida como texto poético. Contudo, cabe pontuar que em música, conforme Adolfo (1997), nem todas as letras funcionam como poesia e, nesse sentido, nem todo poeta é letrista e vice-versa. Existem músicas, de acordo com o autor, em que a poesia toma o papel principal, mas, às vezes, mesmo sendo uma bela poesia, não proporciona um resultado final musical. A letra precisa ter ritmo e sonoridade, tem que estar entrosada com a música em si.

Adolfo (1997) afirma que “a poesia nasceu com a música e isso é confirmado pelos próprios poetas" (p.40). Na Idade Média, os trovadores mesclavam os poemas líricos que eram justamente feitos para serem cantados acompanhados de instrumentos musicais. Nessa época, a poesia ainda não estava separada da música. Conforme Adolfo (1997) "existem hoje poesias musicais que podem ser letradas e inseridas na música popular, e outras mais difíceis para tal [...]. Traduzir som em letra é uma ponte difícil" (p.40). 
Há correntes no campo disciplinar da Música que são controversas em relação à letra da música poder ou não ser considerada poesia. Há quem diga que sim, há quem diga que não. E há ainda quem defenda a ideia de que são coisas diferentes, mas que podem acontecer ao mesmo tempo ou se complementar. Reflexões futuras em novos estudos poderão aprofundar melhor essa questão, inclusive na interface com a prática de tradução poética de músicas para Libras. Nesse estudo, por ora, a letra da música, quando traduzida para a língua de sinais, é passível de ser entendida como texto poético ou um texto de possibilidades e de recursos poéti$\cos$.

A construção poética em Libras é indiscutivelmente possível, prova disso é o grande número de poesias sinalizadas que circulam na comunidade surda, bem como as crescentes publicações e pesquisas que abordam esse assunto. A poesia em línguas de sinais oferece inúmeros recursos para traduções musicais, uma vez que se trata de uma forma de sinalização criativa e artística. Para Sutton-Spence e Quadros (2006, p. 147),

\begin{abstract}
O uso criativo da língua de sinais para produzir novos sinais tem sido chamado também 'sutileza poética' e é relacionado à maneira com que os sinalizantes podem produzir imagem visual forte pelo tratamento criativo da forma visual dos sinais [...]. Um poeta usando sinais visualmente criativos para produzir imagem visual forte está celebrando o potencial visual da língua de sinais. (SUTTON-SPENCE \& QUADROS, 2006, p.147)
\end{abstract}

Recursos poéticos são pesquisados de forma aprofundada e sistematizada por Sutton-Spence (2005). Em seus trabalhos, a autora investiga sobre: repetição e suas variações (repetição de movimento, de locação, de tempo, de sinais, de estruturas gramaticais) ritmo, simetrias (vertical, horizontal), assimetrias, neologismos e suas motivações visuais, soletrações manuais diferenciadas, morfismos, personificação, ambiguidade, motivação visual dos sinais, uso diferenciado do espaço de sinalização etc.

A tradução de poesia, conforme Weininger (2012) é considerada a mais difícil entre as traduções, isso porque geralmente envolve um texto condensado altamente expressivo; a diagramação e elementos grafológicos; efeitos sonoros e rítmicos; a necessidade de interpretações para além do 
significado usual dos elementos linguísticos empregados; o uso de símbolos e metáforas; restrições formais que limitam a escolha de palavras e, também, possíveis desvios das normas linguísticas usuais.

Para Weininger (2012), o texto poético ergue um universo textual em si consistente e autossuficiente. "O texto poético e trabalhado, depurado e aprimorado de modo bem mais intenso do que outros textos" (p.193). Nas traduções poéticas "convém dedicar a devida atenção a cada elemento, analisar sua contribuição ao todo nos vários níveis de análise: sonoridade, ritmo, denotação, conotação, valor metafórico e simbólico, grau de coloquialidade ou rebuscamento, rima, métrica etc." (p.208).

Textos poéticos, para o autor, oferecem comumente segundas interpretações, ou seja, possibilidades de leituras divergentes ou significados alternativos. "A leitura criteriosa do texto de partida e a análise do maior número possível de leituras diferentes podem contribuir para manter a possibilidade dessas leituras em aberto no texto traduzido" (p.211). Os textos poéticos também compreendem o uso recorrente de metáforas e linguagem simbólica e o efeito que esses elementos causam no texto original nem sempre são fáceis de reproduzir no texto traduzido. Além disso, esse gênero textual pode compreender inversões da ordem normal dos elementos, supressão de sílabas dentro de palavras, grafias divergentes, inadequações sintáticas etc., todos esses elementos que devem ser considerados e devidamente analisados pelo tradutor.

Campos (1986) inclui as traduções de poesia dentro de uma tipologia mais abrangente, a de tradução de textos artísticos que, por sua vez, pode ser entendida como uma classificação que também compreende traduções de músicas. Campos (1986) considera que a tradução de textos artísticos costuma ser a que apresenta mais dificuldade para o profissional. Para o autor,

Toda a comunicação artística já é sempre formulada em duas línguas, como sugere Edward Balcerzan: na língua natural e na língua da tradição literária de uma dada civilização. E é mais ou menos óbvio que uma tradução satisfatória da obra de arte literária, assim produzida, há de requerer do tradutor uma aptidão artística à altura. (p.59) 
Campos (1986) aponta os textos poéticos e os textos dramáticos como os mais complexos de se traduzir. "Há quem diga que poemas só devem, ou só podem, ser traduzidos por poetas; e há quem diga que peças de teatro só podem, ou devem ser traduzidas por pessoas ligadas ao teatro" (p.60). O autor considera que, no caso da poesia, essa exigência explica-se pelo fato de o tradutor, além de precisar dominar a língua fonte e a língua alvo da tradução, precisa também de um razoável domínio da técnica de versejar (fazer versos) que, algumas vezes, confunde-se com a arte da poesia. Já os textos teatrais compreendem dois tipos de discurso conforme o autor: as falas dos personagens e as rubricas e indicações do autor. Dessa forma, para se traduzir um texto teatral, o tradutor terá que ter também conhecimento de algumas técnicas teatrais, de interpretação, de montagem e de encenação. Nesse contexto, essas inferências também podem ser aplicadas ao trabalho de tradução de músicas. O profissional que trabalha com língua de sinais precisa conhecer os diferentes aspectos relacionados à música, à poesia e às artes performáticas.

Conforme apresentamos em Rigo e Taffarel (no prelo), para instrumentalização de TILS e desenvolvimento de habilidades que possam atenuar possíveis dificuldades com o uso de recursos poéticos e artísticos para o trabalho com traduções musicais de Português para Libras, sugerimos aos profissionais um contato mais próximo com a arte e com a literatura surda, de modo a consumir mais e conhecer melhor as produções culturais dos surdos, e também se envolver de forma mais participativa com oficinas, workshops, eventos culturais e festivais de caráter formativo dessa área. Recomendamos também práticas imersivas; o contato mais frequente com smooth signers ${ }^{3}$; a proposição e realização de trabalhos em equipe com tradutores e consultores surdos e, ainda, o exercício artístico individual (sem obrigação comercial ou de publicação/divulgação) para o treinamento e aprimoramento da proficiência linguística criativa.

\footnotetext{
${ }^{3}$ Em uma tradução literal: "sinalizantes suaves". Conforme Bahan (2006) smooth signers são performers surdos, artistas da língua, com alto nível de habilidade para contação de histórias, poesia e arte sinalizada, capazes de fazer as expressões mais complexas parecerem as mais simples e belas.
} 


\section{Considerações finais}

Diante das considerações apresentadas, cabe considerar que tradução de músicas de fato não se trata de uma prática simples. Pelo contrário, por compartilhar em maior e menor grau de todas as peculiaridades presentes na tradução poética e nas poesias em língua de sinais, caracteriza-se como um tipo de prática desafiadora; mais ainda quando no processo estão envolvidas línguas de modalidades diferentes, assim como um público que, em geral, possui percepções musicais e entendimentos sonoros bastante peculiares.

Com foco na tradução poética de música para língua de sinais, busquei neste artigo apresentar de forma bastante objetiva, algumas considerações sobre tradução de música de Português para Libras, considerando a perspectiva de tradução poética e o emprego de recursos da poesia em língua de sinais. As considerações apresentadas aqui são baseadas em estudos atuais da área, que se inscrevem no campo dos Estudos da Tradução e Interpretação de Línguas de Sinais (ETILS) e complementam as reflexões compartilhadas em Rigo (2013), contribuindo com profissionais TILS que se atuam com traduções de música de Português para Libras e que transitam profissionalmente pelo contexto artístico-cultural.

\section{Referências}

ADOLFO, A. Composição: uma discussão sobre o processo criativo brasileiro. Rio de Janeiro: Editora Lumiar, 1997.

ANDERSON, R. L. Visual Music: Interpreting Songs in American Sign Language. Bloomington, Indiana: Autor House, 2009.

BAHAN, B. Face-to-Face Tradition in the American Deaf Community: dynamics of the teller, the tale and the audience. In: BAUMAN, H. L; NELSON, J. L; ROSE, H. M. (Ed.) Signing the Body Poetic: essays on American Sign Language Literature. University of California Press, 2006. CAMPELLO, A. R. S. Pedagogia Visual na Educação de Surdos. Tese (Doutorado em Educação). Universidade Federal de Santa Catarina. Florianópolis, 2008.

CAMPOS, G. Como fazer tradução. Petrópolis: Vozes, 1986. 
DEAN, R. K; POLLARD, R. Q. Application of demand control theory to sign language interpreting: implications for stress and interpreter training. University of Rochester School of Medicine. Oxford University Press, 2001.

FOMIN, C.F. R. O tradutor intérprete de Libras no teatro: a construção de sentidos a partir de enunciados cênicos. Dissertação (Mestrado em Linguística Aplicada e Estudos da Linguagem). Pontifícia Universidade Católica de São Paulo. São Paulo, 2018.

GANZ HORWITZ, M. Demands and Strategies of Interpreting a Theatrical Performance into American Sign Language. Journal of Interpretation: Vol. 23: Iss. 1, Article 4, p.1-18, 2014.

HUMPHREY, J.; ALCORN, B. So You Want To Be An Interpreter? An Introduction to Sign Language Interpreting. 4th Ed. Seattle, WA: H \& H Publishing Co., 2007.

KLIMA, E. S.; BELLUGI, U. The signs of language. Cambridge, Mass.: Harvard University Press, 1979.

NAPIER, J.; MCKEE, R.; GOSWELL, D. Sign Language Interpreting: theory \& practice in Australia and New Zealand. Sydney: The Federation Press, 2006.

PIZZUTO, E. [et al]. Dêixis, Anáfora e Estruturas Altamente Icônicas: evidências interlinguísticas nas línguas de sinais. In: QUADROS, R. M; VASCONCELLOS, M. L. (Org.) Questões Teóricas das Pesquisas em Línguas de Sinais. Petrópolis: Arara Azul, 2006.

PIAUÍ, Revista. Descoberto o Homem que Compreende Gilberto Gil. Blog The I-Piauí Herald. Diretor de Redação: Olegário Ribamar. Categoria Cultura. 18 dez. 2009.

PROMETI, D. Glossário Bilíngue Musical: instrumento para atuação de tradutores e intérpretes na educação musical de surdos. In: RIGO, N. S. Textos e Contextos Artísticos e Literários: tradução e interpretação em Libras. v. 2. Petrópolis: Arara Azul (no prelo).

RIGO, N. S. Tradução de Canções de LP para LSB: identificando e comparando recursos tradutórios empregados por sinalizantes surdos e ouvintes. Dissertação (Mestrado em Estudos da Tradução). Universidade Federal de Santa Catarina. Florianópolis, 2013. 
RIGO, N. S. Tradução da peça “O Som das Cores” para Língua Brasileira de Sinais. In: Colóquio Internacional FITA, 1, 2014, Florianópolis. Anais do I Colóquio Internacional FITA. Florianópolis: UFSC, 2014.

RIGO, N. S. Reflexões sobre o contexto artístico-cultural de atuação do tradutor-intérprete de língua de sinais. Revista Guará, Goiânia, v. 8, n. 1, p. 31-41, jan./jun. 2018.

RIGO, N. S.; TAFFAREL, P. Exigências do contexto artístico-cultural: caminhos para atenuar dificuldades enfrentadas por tradutores e intérpretes de língua de sinais. In: RIGO, N. S. Textos e Contextos Artísticos e Literários: tradução e interpretação em Libras. v. 2. Petrópolis: Arara Azul (no prelo). RODRIGUES, C. H. Da interpretação comunitária à interpretação de conferência: desafios para formação de intérpretes de língua de sinais. Anais do II Congresso Nacional de Pesquisas em Tradução e Interpretação de Libras e Língua Portuguesa. Florianópolis, 2010.

RODRIGUES, C. H.; BEER, H. Os Estudos da Tradução e da Interpretação de Línguas de Sinais: novo campo disciplinar emergente? Cadernos de Tradução. Florianópolis, v. 35, no especial 2. P. 1745 jul-dez, 2015.

SANTANA, N. G. Tradução intersemiótica de música para Libras: recursos linguísticos e procedimentos técnicos de tradução possíveis. In: RIGO, N. S. (Org.). Textos e Contextos Artísticos e Literários: tradução e interpretação em Libras. v. 1. Petrópolis: Arara Azul, 2019.

SILVA NETO, V. S. A formação de tradutores de teatro para Libras: questões e propostas. Dissertação (Mestrado em Estudos da Tradução). Universidade de Brasília. Brasília, 2017.

SUTTON-SPENCE, R. Analysing Sign Language Poetry. Basingstoke: Palgrave Macmillan, 2005.

SUTTON-SPENCE, R.; QUADROS, R. M. Poesia em Língua de Sinais: traços da identidade surda. In: QUADROS, R. M. (Org.) Estudos Surdos I. Petrópolis: Arara Azul, 2006.

TAFFAREL, P. Tradução e interpretação em Libras no contexto artístico de Santa Catarina: um mapeamento da região do Vale do Itajaí. Trabalho de Conclusão de Curso (Graduação em Letras-Libras). Universidade Federal de Santa Catarina. Florianópolis, 2018. 
VILAS BOAS, L.; OLAH, N. Luz, câmera, tradução: um relato de experiência sobre a produção de vídeos musicais em Libras. In: RIGO, N. S. (Org.). Textos e Contextos Artísticos e Literários: tradução e interpretação em Libras. v. 1. Petrópolis: Arara Azul, 2019.

WEININGER, M. J. Algumas reflexões inevitáveis sobre a tradução de poesia. In: BLUME, R. F.; WEININGER, M. J. (Orgs.). Seis Décadas de Poesia Alemã: do pós-guerra à atualidade. Florianópolis: UFSC, 2012.

\title{
Resumo
}

Este artigo possui como foco a tradução poética de músicas para línguas de sinais. O objetivo é apresentar considerações sobre tradução de música de Português para Libras considerando a perspectiva de tradução poética e o emprego de recursos da poesia em língua de sinais. As considerações apresentadas são complementares a pesquisa Rigo (2013) e baseiam-se em referências da área dos Estudos da Tradução e dos Estudos da Tradução e Interpretação de Línguas de Sinais. Este artigo soma as demais investigações da área e contribui com profissionais tradutores e intérpretes de língua de sinais que atuam com traduções de músicas de Português para Libras no contexto artístico-cultural.

Palavras-chave: Tradução; Música; Língua de Sinais.

\begin{abstract}
This paper focuses on the poetic translation of songs into sign languages. The aim is to present considerations on translating music from Portuguese to Libras considering a perspective of poetic translation and the use of sign language poetry. The considerations presented are complementary to the Rigo (2013) research and are based on references from Translation Studies and Sign Language Translation and Interpretation Studies. This paper adds to other research in the area and contributes to professional sign language translators and interpreters who work with translations from Portuguese into Libras in performing art settings.
\end{abstract}

Keywords: Translation; Music; Sign Language. 